\title{
DIE ABBA-BELEWING BY JESUS
}

ONS belewe vandag woelige tye. Nie alleen in die politiek nie maar ook in die teologie. Verskillende rukwinde in die veld van die teologie het ons al geskok. Eers was daar die God-is-dood-teologie van Th. J. J. Altizer e.a. Daarna het soos 'n aandwindjie die teologie van die hoop gekom. Wat egter eers as 'n gesuis van 'n sagte koelte gelyk het, het langsamerhand oorgegaan in 'n orkaan wat stormsterkte bereik het in die teologie van die rewolusie van J. Moltmann. Gevolg hiervan was weer ' $n$ wind uit ander rigting $\mathrm{nl}$. die teologie van verontrusting van $W$. Aalders. Uit Amerika het 'n swart teologie na ons kontinent oorgewaai. In die laaste tyd waai daar weer nuwe teologiese winde in die sg. teologie van die goeie daad. ${ }^{1}$

In hierdie teologie val die klem op die goeie daad, dit maak nie saak of daardie daad konfessioneel, teologies of ideologies gemotiveer is nie. ${ }^{2}$ Wie aandagtig kennis neem van die teologie van die goeie daad, sal opmerk dat daar 'n duidelike aksentverlegging plaasvind van die Christelike na die humane. Ontwikkelingshulp, bestry. ding van rassisme, bevryding van die gekolonialiseerde mens is almal Christelike dade. Christelik is 'n kwaliteit van die humane en nie omgekeerd nie. So 'n siening op dade van humaniteit moet die Christelike religie noodwendig relativeer. Die boek van H. M. Kuitert, Zonder geloof vaart niemand wel, is hiervan 'n duidelike voorbeeld.

In die konteks van die teologie van die goeie daad waarin die humane so sterk beklemtoon word ten koste van die Christelike kry die persoon van Jesus ook 'n nuwe plek. Hy is die Bevryder, die groot Rewolusionêr, die „Partijganger der armen”. Om alles wat buitekant die kerk en die Christendom aan goeie dade plaas vind tog nog teologies te motiveer, word daar gespreek van „Jesusincognito" en van 'n „Christendom buitekant die kerk".

So 'n benadering het vanselfsprekend gevolge vir die Christologie, die leer aangaande Christus. Is Christus alleen mens of is Hy ook God?

In die laaste drie jare het daar op die teologiese boekemark verskillende boeke verskyn waarin opnuut besondere aandag gegee is aan die verskyning van Jesus in die wêreld. Daar is die "Neues Glaubensbuch" wat in 1973 verskyn het en deur J. Feiner en L. Vischer geredigeer is. Ook het in die Duitse taalgebied 'n nuwe boek van Hans Küng op die mark gekom: Christ sein (1974). In Nederland het die boek van $H$. Berkhof: Christelijk geloof (1973) as 'n skok gekom, gevolg deur die werk van E. Schillebeeckx: Jezus, het verhaal van een levende (1974).

Met name in die beide boeke van Berkhof en Schillebeeckx ontdek ons 'n Christologie vanuit die mens Jesus, 'n Christologie „van onderen op". Die mensheid van Jesus word so sterk benadruk dat die godheid van Christus in die gedrang kom. H. Berkhof dui Christus aan as „de wortel en ook de horizon van deze door God 
bedoelde humaniteit" (p. 557). Daar is volgens Berkhof tussen Jesus en God wel 'n volmaakte wilseenheid maar daar is geen wesenseenheid nie. Jesus is 'n nuwe skeppingsdaad van God, Hy is die volmakte verbondspartner.

Ook Schillebeeckx maak in sy boek oor Jesus gebruik van die histories-kritiese metode van Skrifondersoek om met behulp van die sg. Traditionsgeschichte te kom tot 'n suiwere Jesus-beeld. Die resultaat is 'n Jesus-beeld wat die moderne mens aanspreek en waarin die klem op die menslike val. Selfs datgene wat ons as 'n historiese kern uit die tradisie-stof kan aanvaar, wys ons op Jesus se "schepselijke status als mens” (p. 533).

Aan die einde van Schillebeeckx se boek oor Jesus blyk dit tog dat hy minder konsekwent is as Berkhof. Berkhof wys die godheid van Christus radikaal af. Jesus is alleen mens, ,de door God aan ons gegeven nieuwe mens", ${ }^{3}$ terwyl Schillebeeckx tog nog moet erken dat Jesus „in volmaakte eenheid met de Vader” sy seunskap belewe. ${ }^{4}$

Sowel Berkhof as Schillebeeckx probeer om langs die pad van die histories-kritiese ondersoek tot die juiste beeld te kom van die historiese Jesus. Berkhof erken egter dat 'n mens met hierdie metode tog nie tot die geheim van Jesus kan deurdring nie. ${ }^{5}$

Veral vir Schillebeeckx is daar baie in die berigte oor Jesus se persoon en sy optrede wat net interpretasie is en waarvan die historisiteit bevraagteken moet word.

Maar - en dit bring ons by ons onderwerp - daar is volgens Schillebeeckx een gebeurtenis in Jesus se lewe wat as 'n historiese kern aanvaar moet word en dit is die Abba-ervaring. ${ }^{\circ}$

Hier moet - aldus Schillebeeckx - die Nieu-Testamentikus eerbiedig swyg. Jesus se gebruik van die woord Abba is so iets unieks, so iets persoonliks dat ons dit eintlik nie kan ontraaisel nie. Ook weet ons nie of hierdie woord wel in 'n algemene religieuse kategorie pas nie.?

Selfs mense soos Berkhof en Schillebeeckx moet daarom erken dat ons by die Abba-ervaring van Jesus staan voor 'n geheel besondere gebeurtenis. Ten eerste moet hulle erken dat dit 'n historiese gebeurtenis is en ten tweede dat hierin die unieke toewyding van Jesus tot die Vader aan die orde kom.

Jesus noem God in 'n uitsonderlike vertroulikheid „Abba". Kragbron van Jesus se lewe is 'n gereelde en intensiewe gebedsverkeer waarin Hy God met "Abba” aanspreek. Hoewel hierdie verhouding tussen Jesus en God geheel eiesoortig is, wil Hy tog ook mense in die geheim van hierdie vertroulike omgang laat deel (vgl. Matt. $11: 27$ ).

Dit is die rede wat ons aandag wil gee aan die woord „Abba” en dat ons 'n ondersoek wil instel na die openbaringshistoriese betekenis van hierdie begrip. Die groot vraag waar alles om draai, is of ons uit die woord Abba in die mond van Jesus die godheid van Christus kan aflees? Onthul Jesus se Abba-belewing aan ons die godheid van sy Persoon? 


\section{Die moedertaal van Jesus}

Die woord „Abba" bring ons by die moedertaal van Jesus. Watter taal het Jesus as Kind van sy moeder Maria geleer en in watter taal het Hy, die Seun van God wat mens geword het, sy gedagtes tot uitdrukking gebring en sy prediking laat hoor? Wyle prof. S. J. du Plessis het by die aanvaarding van 'n professoraat in Semitiese tale aan die P.U. vir C.H.O. 'n inougurele rede gelewer oor die moedertaal van Jesus waarin hy tot die konklusie gekom het dat Jesus 'n dialek van Hebreeus gepraat het. ${ }^{8}$ Nie die Hebreeus van die O.T. of die Dooie See-rolle of die Misna-Hebreeus nie, maar die Hebreeus van die breë volkslae in die tyd van sy omwandeling op aarde. ${ }^{\circ}$ S. Greijdanus is van oordeel dat Jesus Grieks goed magtig was en byvoorbeeld tot die Siro-Fenisiese vrou in Matt. 15:22 Grieks gepraat het, maar ,bij zijn spreken tot de Joodse scharen heeft $\mathrm{Hij}$ gewoonlijk wel van de landstaal, het Aramees gebruik gemaakt". 10

Prof. S. du Toit het sy siening oor hierdie saak soos volg vertolk: "In die tyd van die omwandeling van Jesus was Hebreeus reeds lank nie meer die lewende taal van Palestina en aangrensende gebiede nie. Elke Jood het Aramees dus as sy moedertaal geleer, en eers wanneer hy groot genoeg was om te kan lees en skrywe, het Hebreeus bygekom".11

Navorsing op hierdie gebied deur manne soos $\mathrm{J}$. Welhausen, P. Joüon en M. Black het aan die lig gebring dat die moedertaal van Jesus Aramees was en dan spesiaal Wes-Aramees, 'n taal wat in Galilea gepraat is en wat verwant was aan Hebreeus. ${ }^{12}$ Uit die sg. logia van Jesus hoor ons verskillende woorde wat in Aramees aan ons oorgelewer is soos byvoorbeeld Talita koemi (Mark. 5 : 41), Effata (Mark. $7: 34$ ), raka (Matt. $5: 22$ ) en ook die woord Abba in Mark. 14 : 36. Die woord pasga is ook 'n Aramese woord en ten slotte is ook die kruiswoord Eloi, Eloi, lamma sabagtani in Aramees uitgespreek (Mark. $15: 34$ ).

Dat Jesus in sy moedertaal gespreek het, dit was vir die mense van sy tyd nie so vreemd nie. Maar dat Jesus uit sy moedertaal woorde kies om God aan te spreek en om Hom aan mense te openbaar, dit was werklik opsienbarend en selfs skokkend. Die mees skokkende en opsienbarende in die prediking van Jesus was wel die gebruik van die Aramese woord Abba. Met hierdie woord het Jesus nl. God as Vader aangedui.

\section{Die gebruik van „Abba” by die Jode}

Dit was heeltemal ongebruiklik by die Jode om die woord Abba te gebruik wanneer ' $n$ mens God aanspreek of as daar oor God gepraat word, nie in die gebed nie, maar ook nie in die prediking nie.

Hoewel die antieke Jodedom 'n groot rykdom van Godsaansprake gehad het, was die aanspreekvorm „Vader" nie daarby aanwesig nie. Wel is God in liturgiese gebede as Vader aangespreek maar dan tog altyd in die betekenis van Koning: "abinu malkenu", onse Vader, onse Koning. ${ }^{13}$ Die persoonlike aanspreekvorm „Vader" soek ons tevergeefs. 
Daarom is dit heeltemal ongewoon en selfs bevreemdend dat Jesus volgens die Evangelies God aanspreek as Vader. Dit moet nog meer bevreemding wek wanneer ons hoor dat Jesus die Aramese aanspreekvorm Abba gebruik.

In Mark. 14 : 36 is die woord Abba uit die mond van Jesus uitdruklik aan ons oorgelewer. Dat Jesus ook in sy ander woorde en gebede die woord Abba gebruik het, blyk uit die Griekse tekste wat aan ons oorgelewer is. Dit is nl. besonder opvallend dat Jesus in dieselfde gebed in Matt. 11 : 25 e.v. sowel die vokatief pater as ook die nominatief patèr gebruik. Dit wys vir ons dat agter die Griekse woord die Aramese woord Abba lê, omdat met name in die Aramese taal Abba as ' $n$ mengvorm vir sowel die nominatief as die vokatief gebruik is. ${ }^{14}$

Hoekom was die Jode nou so skrikkerig om die woord Abba te gebruik? Die eenvoudige rede is dat die woord abba oorspronklik net gehoor is uit die kindermond. Abba is kindertaal. 'n Kind het op sy kinderlike, vertroulike manier aangespreek as abba. Ons sou dus abba kon vertaal met pa of pappa of pappie. Abba is eintlik 'n brabbelwoord.15

In die Talmud word gesê: „Wanneer 'n kind gespeen is en die smaak van brood gewoond geraak het, leer hy om abba en imma te sê". ${ }^{10}$ Dit was vir die Jode ergerniswekkend dat Jesus dit gewaag het om die hoë, heilige God op so 'n manier aan te spreek en Hom Abba te durf noem. Ons kan dus aanvaar dat die woord Abba uit die mond van Jesus behoort tot die ipsissima verba Jesu.

Hierdie woord Abba in die mond van Jesus ontvou vir ons die diepste geheim van sy lewe. Hy kan, Hy mag die Skepper van hemel en aarde op hierdie wyse aanspreek. Hy mag God Abba noem en so openbaar Hy wie God vir Hom is: Vader. Wanneer gevra word: wie was die historiese Jesus?, dan kan ons antwoord: Dit was Hy wat die mag, die voorreg gehad het om God Abba in kinderlike tederheid en afhanklikheid te noem. Dit was ook Hy wat sondige mense leer om hierdie woord Abba op hulle lippe te neem wanneer hulle God aanspreek.

\section{Drie motiewe}

Wanneer gevra word: wat het Jesus daartoe gelei om hierdie ons kan amper sê - uitdagende term Abba te gebruik wanneer $\mathrm{Hy}$ sy Vader aanspreek of wanneer Hy oor sy Vader tot mense spreek? Dan kan ons sê dat drie motiewe Hom gelei het om sowel in sy gebed as in sy prediking hierdie woord aan te wend. Die motiewe is die openbaringsmotief, die vervullingsmotief en die uitnodigingsmotief. ${ }^{17}$

In die eerste plek gebruik Jesus hierdie opsienbarende term Abba in sy spreke met God en in sy spreke oor God om sy unieke verhouding tot die Vader tot uitdrukking te bring. Dit is die openbaringsmotief. Jesus openbaar in hierdie woord sy besondere verhouding tot God. Jesus kan God sy Vader noem, omdat God sy Vader is in eintlike en unieke sin. Die geheim van sy goddelike Seunskap word hierin onthul. Twee voorbeelde om dit aan te toon: 
In Matt. 11 : 25 e.v. kan Jesus God Abba noem, omdat sy Vader alles aan Hom oorgegee het en omdat niemand die Vader ken nie behalwe die Seun. Uit die gebedswoorde van Jesus kan ons verneem dat Hy op 'n geheel enige wyse die Seun van God is nl. in unieke en eintlike $\sin ^{17}$

Schillebeeckx moet dan ook erken dat in hierdie Abba-belewing van Jesus twee dinge tot uitdrukking kom nl. die unieke toewyding van Jesus tot sy Vader, maar ook die unieke toewyding van die Vader tot Jesus. ${ }^{18}$ Berkhof is van oordeel dat Schillebeeckx hier inkonsekwent is en 'n sprong maak deur vanuit die subjektiewe Abba-ervaring op te styg tot 'n volstrek unieke persoonsrelasie met en binne God. ${ }^{19}$ Berkhof is oortuig dat ons ,met traditionsgeschichtliche middelen niet verder komen dan tot een subjectieve Abba-beleving" by Jesus. ${ }^{20}$ Is dit nie ' $n$ oortuigende bewys dat die metode van die Traditionsgeschichte ten enen male ondeugdelik is nie? Die histories-kritiese metode is ontoereikend om daarmee die Woord van God volledig te kan verklaar.

H. N. Ridderbos skrywe by hierdie gebruik van die woord Abba deur Jesus: „Achter deze ambtelijke verhouding ligt echter nog iets diepers, nl. 'Jezus' wezensgelijkheid met God, die reeds met de woorde mijn Vader wordt aangeduid: Jezus is in geheel eenigen zin de Zoon des Vaders". ${ }^{21}$ In sy boek: Zelfopenbaring en zelfverberging skrywe hy: „Het is dan ook moeilijk voor tegenspraak vatbaar, dat het Zoonschap van Jezus, $66 \mathrm{k}$ volgens de synoptische evangeliën, in geen enkel opzicht te herleiden is tot een, binnen de grenzen van het menschelijke en natuurlijke leven liggende, bizondere religieuze verhouding tot God en iedere poging, om met het ontleedmes der critiek tusschen het natuurlijke en bovennatuurlijke te onderscheiden en het laatste dan als contemporain en onwezenlijk uit te zuiveren, is ijdel". ${ }^{22}$ Wie met die mes van die Traditionsgeschichtliche metode in hierdie teks uit Matt. 11 gaan sny, sny wesentlike dele uit die Skrif uit.

Ook in die hoëpriesterlike gebed in Joh. 17 staan die gebruik van die woord Abba wat ons agter die Griekse teks mag veronderstel, in verband met die unieke verhouding tussen Jesus en sy Vader. Met name in die verse 11 en 21 gaan dit oor die openbaring van die eenheid van die Seun en die Vader.

Die woord Abba dien ook in hierdie gebed ,ter openbaring van het geheimenis van het goddelijke leven". ${ }^{23}$ G. Sevenster is dan ook van oordeel dat ons „bij het een-zijn blijkbaar steeds te doen hebben met een persoonlijke gemeenschap". ${ }^{24}$

Jeremias sê: „Das Abba der Gottesanrede Jesu enthüllt des Herzstück seines Gottesverhältinisses". ${ }^{25}$

Die gebruik van die woord Abba openbaar aan ons die wesenseenheid en wesensgelykheid van Vader en Seun. ${ }^{20}$ Schillebeeckx aarsel om dit te erken ${ }^{27}$ en soos ons gesien het Berkhof verwerp dit radikaal. ${ }^{28}$

Jesus was Homself wel deeglik bewus van sy unieke relasie tot God. Dit moet ons tog tref dat Jesus nooit saam met sy dissipels God aanspreek as „onse Vader" nie. Altyd is daar die treffende onderskeiding tussen „My Vader" en „julle Vader". ${ }^{2 \theta}$ My Vader 
of Abba soos Jesus dit oorspronklik gesê het „drukt de exclusiviteit van zijn Zoonschap uit". ${ }^{30}$

Naas die openbaringsmotief in Jesus se gebruik van die woord Abba is daar ook die vervullingsmotief. Wanneer vanaf die aarde God in die hemel weer met Abba aangespreek word, kan beteken dit dat die oorspronklike bedoeling van God met sy volk gerealiseer gaan word.

Jesus noem God Abba, Vader. Dit is die realisering van Gods bedoeling met sy volk soos ons dit kan lees in Jer. 3: 19: „Ook het Ek gedink: Jy sal My noem: my Vader! en jy sal van My nie afvallig word nie". Ook in Jer. 31 : 9 kom die Vader-wees van God ter sprake.

Jesus se aanspraak van God met Vader is daarom die vervulling van die Ou-Testamentiese profesie. Die aanwending van die woord Abba deur Jesus onthul dat die nuwe bedeling, die messiaanse heilstyd aangebreek het. In hierdie opsig kan ons die woord Abba 'n eskatologiese begrip noem. Wat Abba vertolk, kom in die eskaton tot volle realisering. ${ }^{31}$

In die derde plek is daar ook nog die uitnodigingsmotief. Op die vraag van die dissipels aan Jesus om 'n gebed, aangesien Johannes die Doper sy leerlinge ook 'n gebed gegee het (Luk. $11: 1$ ) gee Jesus vir hulle die Onse Vader. Jesus voldoen aan die versoek van sy leerlinge en Hy gee hulle die toestemming om God ook as Abba aan te spreek, want volgens die lesing van Lukas sê Jesus eenvoudig: Pater, Vader. Die Griekse woord Pater is die ekwivalent van Abba. Die dissipels ontvang toestemming om God ook as Abba, Vader aan te spreek. Jesus laat hulle dus partisipeer in sy eie gemeenskap met God.

In verband met hierdie uitnodigingsmotief skrywe J. Jeremias: „Here we see who the historical Jesus was: the man who had the power to adress God as Abba and who included the sinners and the publicans in the kingdom by authorizing them to repeat this one word, 'Abba', dear Father".32

\section{Die inhoud van die Vader-kind-verhouding}

Wanneer ons vervolgens vra na die inhoud van die Vader-kindverhouding soos dit in die woord Abba tot uitdrukking kom, dan is daar twee belangrike sake wat dadelik opval nl. vergewing en versorging.

Ons vind in die N.T. 'n noue verwantskap tussen die Vaderskap van God en die vergewing van sondes. Wanneer ons let op die gelykenis van die verlore seun in Lukas 15 dan vind ons in daardie gelykenis van Jesus twee brandpunte: vergewing van sondes en die Vaderskap van God.

Ook in die Bergpredikasie tref ons dieselfde twee pole aan (Matt. $6: 14,15$ ). In verband hiermee skrywe $H$. N. Ridderbos: „Men kan zeggen dat de vergeving der zonden de veronderstelling vormt van de verhouding Vader-kind, zoals Jezus die in zijn prediking op God en zijn volk toepast. Omgekeerd is het Vaderschap Gods en het kindschap der gelovigen de realisering van de gemeenschap in welke de vergeving der zonden tot stand kwam".ss 
Gods natuurlike gawes is vir almal. Hy laat sy son opgaan oor slegtes en goeies, en Hy laat reën op regverdiges en onregverdiges (Matt. 5 : 45). Maar sy geestelike gawes, die vergewing van sondes en die ewige lewe, is net vir sy kinders, vir hulle wat Hom aanroep, wat Hom as Vader eerbiedig, erken en huldig.

Ons moet altyd onthou dat daar 'n prinsipiële verskil is tussen die Vaderskap van God soos Jesus dit verkondig en soos ons dit vind in die buite-Christelike religies. In die buite-Christelike godsdienste gaan dit op die ou end altyd om die vergoddeliking van die mens en om verlossing van die mens uit sy materiële en tydelike bestaanswyse. ${ }^{34}$

Hierdie Vader-kind-verhouding soos die N.T. dit verkondig, moet ons in openbaringshistoriese sin verstaan nl. as die realisering van die belofte van die Nuwe Verbond: die voortsetting en vervulling van die band tussen Jahweh en Israel.35

In die Vader-kind-verhouding soos dit in die woord Abba tot uitdrukking kom, word naas Gods vergewing ook sy versorging bekend gestel. Soos 'n Vader sal God vir sy kinders, vir almal wat Hom as Abba aanspreek, sorg. Julle Vader wat in die hemele is, sal goeie dinge gee aan die wat Hom bid, wat Hom aanroep as Abba (Matt. $7: 11$ ) ${ }^{36} \mathrm{Hy}$ wat geleer het om God aan te spreek as Abba, mag deel in die geheimenis wat Jesus as Seun geopenbaar het en so ook mag hy deel in die deur Jesus gerealiseerde heilstyd. ${ }^{37}$

Jesus het die reg gehad - soos B.M.F. van Israel dit noem "geheel vanzelfsprekend" God as Abba aan te spreek, ${ }^{38}$ want Hy is die Seun van God in unieke en eintlike sin. Vir die mens lê dit heeltemal anders.

In sy insiggewende studie oor die woord Abba sê J. Jeremias dat die Abba-roep buite elke menslike moontlikheid lê. Dis vir sondige mense eenvoudigweg onmoontlik om God met hierdie vertroulike woord aan te spreek. ${ }^{38}$

Hoe sal ons, van God vervreemde mense ingaan in hierdie heerlike Vader-kind-verhouding wat Jesus met die woord uit die kindertaal vir ons bekendstel en ook vir ons oopstel? Die antwoord op hierdie vraag kry ons by Paulus. Sowel in sy brief aan die Romeine $(8: 15)$ as ook in sy brief aan die Galasiërs $(4: 6)$ lees ons dat die apostel die Abba-term ken en gebruik.

\section{Die gebruik van Abba by Paulus}

Wanneer ons die briewe van Paulus oopslaan dan lees ons dat in die eerste Christelike gemeente die term Abba in gebruik was. Sowel in die erediens as ook in die persoonlike gebedslewe is hierdie aanspreekvorm vir God gebruik.

In Mark. $14: 36$ het ons Jesus hoor bid met die woord Abba, terwyl Markus vir sy nie-Joodse lesers dadelik die vertaling van hierdie Aramese woord daar aan toe voeg. Paulus doen dieselfde in sy brief aan die Romeine en sy brief aan die Galasiërs. ${ }^{40}$ In die eerste Christelike gemeente is sowel in persoonlike gebede as ook in die liturgie van die kerk die woord Abba gebruik. ${ }^{41}$

Die Griekse toevoeging by die Aramese woord is as vertaling bedoel, maar dit is ook moontlik dat beide die Aramese en die 
Griekse woord vir Vader deur die gelowiges in hul gebede uitgespreek is en dat die apostel die aanspraak deur die Christene uit die Jode en die aanspraak deur die gelowiges uit die heidene naas mekaar geplaas het om op hierdie wyse die eenheid tussen beide woorde aan te dui. ${ }^{42} \mathrm{~S}$. Greijdanus is van oordeel dat ons hier moet dink aan die „Onse Vader" wat deur die gelowiges en die gemeente gebid is. ${ }^{43}$

Hoe is dit moontlik dat sondige mense wat die oordeel van God verdien het tot hierdie vertroulike en innige aanspraak van God kan kom? Paulus antwoord: dis die werk van die Heilige Gees. ,Julle het die Gees van anneming tot kinders ontvang deur wie julle roep: Abba" (Rom. $8: 15$ ). „Omdat julle kinders is, het God die Gees van sy Seun in julle harte gestuur, en Hy roep: „Abba” (Gal. $4: 6$ ).

Ons het hier te doen met twee parallelle tekste van Paulus. Dit blyk uit die konteks. Die gedagtegang is in die konteks van beide verse dieselfde. Paulus sê in beide tekste dat die Gees ons leer „roep". Hy gebruik dan die werkwoord „krazein”. In hierdie werkwoord lê die gedagte van om te roep en dan besonder om te roep vanuit die nood. Dit gaan nie primêr om „een luide roepen” nie soos Greijdanus verklaar, ${ }^{44}$ maar teen die Ou-Testamentiese agtergrond van hierdie woord om 'n roep uit die diepte, uit die nood. ${ }^{45}$

By alle punte van ooreenkoms tussen Rom. 8:15 en Gal. 4:6 is daar tog ook 'n verskil wat nie oor die hoof gesien mag word nie. Sommige eksegete gaan sover om 'n tydsverskil tussen hierdie twee tekste te konstrueer. Dit sou dan in Gal. 4:6 gaan oor die roep van die Gees en in Rom. 8:15 oor die roep van die gelowige. Eers roep alleen die Heilige Gees Abba, die gelowige hoor dit en daarna begin hy in navolging van die roep van die Gees ook God aan te spreek met Abba. ${ }^{40}$

Op hierdie wyse word egter die werk van die Gees en die gebed van die gelowige te veel van mekaar geskei. Daar is tog 'n onlosmaaklike eenheid tussen die werk van die Heilige Gees en die gebed van die gelowige.

Dit is stellig so dat in Gal. 4 : 6 die Heilige Gees roep en dat in Rom. $8: 15$ die gelowige roep: Abba, maar dan moet ons tog daarop let dat die Gees volgens Paulus in ons harte roep. Dis juis die heerlike: die Gees gaan ons voor, Hy ondersteun ons gebed en Hy gee ons die vrymoedigheid om saam met Hom God as Vader aan te spreek. Ons kry dieselfde gedagte in Openb. 22 : 17 waar die Gees en die bruid sê: Kom! Dis die Heilige Gees wat die bruidsgemeente bring tot die verlangende roep om die wederkoms van Christus. Die gebed van die bruid is vrug van die gebed van die Heilige Gees. ${ }^{47}$ In sy kommentaar op die brief aan die Galasiërs beskrywe Luther hierdie Abba-roep van die gelowiges so treffend: (hier volg die Nederlandse vertaling): „Wanneer wij het allerdiepst in zulk een schrik voor de wet staan en de zonde als het ware boven ons dondert, de dood ons doet sidderen en beven, de duivel allergruwelijkst brult, dan begint (zoals de heilige Paulus hier zegt) de Heilige Geest in onze harten te roepen: Abba, lieve Vader. En dit zijn roepen is veel machtiger dan het geroep van wet, zonden, 
dood en duivel, al klinkt het nog zo geweldig en verschrikkelijk. Het roepen van de Geest breekt en dringt met alle macht door wolken en hemel heen, komt voor Gods oren en wordt verhoord".48 Hierdie roep van die Gees is „een ondersteunende aanvulling van het roepen der Gemeente".49

\section{Die Abba-ervaring van die gelowige}

In die woord Abba het ons werklik met teologie te doen, nie met 'n God-is-dood-teologie, dus 'n dooie teologie nie en ook nie met 'n rewolusionêre teologie of 'n teologie van die daad nie. Hier val mos nie die klem op wat die mens doen of op wat die mens moet doen nie, maar hier val die volle nadruk op God, op wat God in Christus Jesus deur sy Heilige Gees vir ons wil wees en wat $\mathrm{Hy}$ as die Drieenige God doen in 'n mensehart. Dit gaan hier dus om die Drieenige God. Die woord Abba staan, soos J. P. Versteeg so treffend aangetoon het, in 'n trinitariese kader. ${ }^{50}$ Dit mak die inhoud, die rykdom en die troos van die begrip Abba so groot. En daarom sal die inhoud, die rykdom en die troos van die woord Abba vir ons verlore gaan, wanneer ons die Abba-belewing van Jesus neerhaal tot die menslike vlak.

Berkhof mag dan spot dat ons wanneer ons uit die Abba-belewing van Jesus sy unieke verhouding tot die Vader wil aflees, by wyse van spreke 'n vliegtuig laat opstyg iewers die metafisiese lug in. ${ }^{51}$ Ons glo dat die woord Abba ons in die eerste plek onthul die wesensverbondenheid van Jesus met sy Vader. Maar tweedens glo ons ook dat hierdie woord Abba vir ons openbaringshistories die rykdom van die verbond en die verbondsgemeenskap van 'n gelowige met sy God en Here verduidelik en in die derde plek aanvaar ons dat die vrymoedigheid wat elke kind van God besit om die woord Abba te mag gebruik 'n heerlike troos bied. Elke ware gelowige kan vir sy persoonlike geloofslewe in die woord Abba en in die gebruik van hierdie woord ook kom tot die heerlike Abbabelewing: by God my Vader in Christus Jesus is vrede, veiligheid en verwagting.

Die N.T. leer ons wat nodig is om Abba te kan sê. Daar is 'n logion van Jesus: „Voorwaar, Ek sê vir julle, as julle nie verander en soos die kindertjies word nie, sal julle nooit in die koninkryk van God ingaan nie!" (Matt. $18: 3$ ).

In die geskiedenis van die eksegese van hierdie teks is daar al baie gestry oor die verklaring van die uitdrukking: „en soos die kindertjies word". Wat is hier die tertium comparationis? Bedoel Jesus hier die kleinheid, die deemoed, die nederigheid van die kind soos J. Schniewind verklaar? ${ }^{52}$ Of moet ons hier dink aan swakheid en hulpbehoewendheid, soos J. M. S. Baljon oordeel? ${ }^{53}$ H. N. Ridderbos op sy beurt sien die punt van vergelyking in die ,schuchter, bedeesd, nederig" wees van 'n kind tussen groot mense. ${ }^{54}$ Fritz Rienecker soek die punt van vergelyking in die armoede. ${ }^{55} \mathrm{~T}$. W. Manson het egter met die gedagte gekom dat die punt van vergelyking op 'n ander vlak gesoek moet word. Hy sê die vergelyking wat Jesus trek tussen die wat die Koninkryk van God sal ingaan en die kindertjies is dit: die kenmerkende van ' $n$ kind is dat hy 
geleer het om abba te sê. Dit moet 'n mens ook leer om die Ryk van God te kan binnegaan. ${ }^{\circ 6}$ Dan sou Jesus hier wil sê: as julle nie geleer het om Abba te sê dan kan julle die Koninkryk van God nie ingaan nie.

L. Floor.

(Gelewer voor G.T.V. Pretoria, Februarie 1976).

1 H. N. Ridderbos: De „minste broeders" van Jezus, in: Geref. Weekblad, 31e Jaargang, No. 22, 28 Nov. 1975, p. 114.

2 L. Floor: Die Koninkryk van God en die vernuwing van die Maatskappy, 1974 , p. $81-84$.

3 H. Berkhof: Over Schillebeeckx' Jezus-boek, in: Nederl. Theol. Tijdschrift, 29e Jaargang, 4e Afl., Okt. 1975, p. 331.

4 E. Schillebeeckx: Jezus, het verhaal van een levende, 1974, p. 543.

5 H. Berkhof: Christelijk geloof, 1973, p. 295.

6 E. Schillebeeckx: a.w., p. 533-535.

7 E. Schillebeeckx: a.w., p. 535.

8 S. J. du Plessis: Die moedertaal van Jesus, in: Koers, No. 3, Jaargang XXXI, Sept. 1963, p. 189.

9 S. J. du Plessis: a.art., p. 190.

10 S. Greijdanus: De toestand der eerste Christelijke Gemeente, 1973, p. 19, 20.

11 S. du Toit: Die Ou Testament 'n Wonder, 1963, p. 107.

12 J. Jeremias: Neutestamentliche Theologie I, 1973, p. 15.

13 J. Jeremias: a.w., p. 69.

14 J. Jeremias: a.w., p. 70.

15 J. Jeremias: a.w., p. 71.

16 Babiloniese Talmud: Traktaat Berachoth 40 a.

17 Die eerste twee motiewe vind ons by J. P. Versteeg: De Heilige Geest en het gebed, 1973 , p. 18 e.v. Die werwingsmotief vind ons by J. Jeremias: The Central Message of the New Testament, 1965, p. 30.

18 E. Schillebeeckx: a.w., p. 535.

19 H. Berkhof: Over Schillebeeckx' Jezus-boek, in: Nederl. Theol. Tijdschrift, 29e Jaargang, 4e Afl., Okt. 1975, p. 328, 329.

20 H. Berkhof: a.art., p. 329.

21 H. N. Ridderbos: Het Evangelie naar Mattheus, Dl. I, 1941, p. 225.

22 H. N. Ridderbos: Zelfopenbaring en zelfverberging, 1946, p. 35. Vgl. ook:

G. Sevenster: De Christologie van het Nieuwe Testament, 1946, p. 99, 101.

23 W. Marcel: Abba, Pére! La prière du Christ et des chrétiens, 19712, p. 165.

24 G. Sevenster: a.w., p. 247.

25 J. Jeremias: Abba, Studien zur neutestamentlichen Theologie und Zeitgeschichte, 1966, p. 63.

26 G. de Ru: Wat dunkt $u$ van de Christus? in: Kerk en Theologie, 26e Jaargang, no. 4, Okt. 1975, p. 295.

27 E. Schillebeeckx: a.w., p. 213.

28 H. Berkhof: a.art., p. 329. Vgl. ook sy: Weerwoord op De Ru en Geense, in: Kerk en Theologie, 26e Jaargang, no. 4, Okt. 1975, p. 319.

29 Vgl. Matt. $6: 14$ met $18: 35$ en Luk. $12: 32$ met $22: 29$. H. N. Ridderbos: De komst van het Koninkrijk, 1950, p. 213; G. Sevenster: a.w., p. 99.

30 H. N. Ridderbos: a.w., p. 213.

31 J. P. Versteeg: a.w., p. 19.

32 J. Jeremias: The Central Message of the New Testament, 1965, p. 30. 


\section{In die Skriflig}

33 H. N. Ridderbos: a.w., p. 208, 209.

34 W. Twisselmann: Die Gotteskindschaft der Christen nach dem Neuen Testament, 1939, p. 10-25, 102-105.

35 H. N. Ridderbos: a.w., p. 211.

36 W. G. Kümmel: Die Theologie des Neuen Testaments, 1972², p. 36.

37 J. P. Versteeg: a.w., p. 30.

38 B. M. F. van Iersel: „Der Sohn” in den synoptischen Jesusworten, 19642, p. 116.

39 J. Jeremias: Abba, Studien zur neutestamentlichen Theologie und Zeitgeschichte, 1966, p. 66 .

40 J. Schniewind: Das Evangelium nach Markus, NTD, 1965, p. 189.

41 H. W. Beyer: Der Brief an die Galater, NTD, 1965, p. 35.

42 S. Greijdanus: De Brief van den apostel Paulus aan de Gemeenten in Galatië, 1936, p. 263, 264.

43 S. Greijdanus: a.w., p. 264.

44 S. Greijdanus: De Brief van den apostel Paulus aan de Gemeente te Rome I, 1933, p. 371.

45 J. P. Versteeg: a.w., p. 12, 13.

46 K. Stalder: Das Werk des Geistes in der Heiligung bei Paulus, 1962, p. 45.

47 W. H. Velema: Het Woord werkt door, 1973, p. 146.

48 M. Luther: Ausf. Erklärung der Epistel an die Galater, Sp. 527 (Nr. 81).

49 P. A. van Stempvoort: Oud en Nieuw, De brief aan de Galatiërs, 1951, p. 116.

50 J. P. Versteeg: a.w., p. 22.

51 H. Berkhof: Over Schillebeeckx' Jezus-boek, in: Nederl. Theol. Tijdschrift, 29e Jaargang, 4e Afl., Okt. 1975, p. 329.

52 J. Schniewind: a.w., p. 196.

53 J. M. S. Baljon: Commentaar op het Evangelie van Mattheüs, 1900, p. 261.

54 H. N. Ridderbos: Het Evangelie naar Matthells II, 1946, p. 40.

55 F. Rienecker: Das Evangelium der Matthäus, 1961, p. 250.

56 T. W. Manson: The Teaching of Jesus, 1963, p. 331. Vgl. ook J. Jeremias: Die Gleichnisse Jesu, 19708, p. 189, 190. 